\title{
DÍVIDA PÚBLICA: ALGUMAS REFLEXõeS
}

\author{
Francisco Pedro Jucá \\ Livre-Docente e Doutor em Direito Público (USP). \\ Doutor em Direito Privado (PUC/SP). Pós Doutorado Universidade \\ de Salamanca (Esp.) e Universidade Nacional de Córdoba (Arg.). \\ Professor Titular da Faculdade Autônoma de Direito de São Paulo - FADISP. \\ Pertence a Academia Paulista de Letras Jurídicas, \\ Academia Paraense da Letras Jurídicas, Academia Paulista \\ de Magistrados, Instituto dos Magistrados Brasileiros, Sociedade Paulista \\ de Direito Financeiro e Academia Nacional de Direito Financeiro. \\ Juiz do Trabalho em São Paulo.
}

\section{SUMÁRIO}

Aspectos referenciais - 1. Vida financeira do Estado - 2. Despesa pública, equilíbrio orçamentário e déficit - 3. Déficit e dívida pública - Conclusão - Referências. 


\section{ASPECTOS REFERENCIAIS}

O exame que se propõe ao tema Dívida Pública busca formar a compreensão primeiramente sistêmica, buscando entender o fenômeno na sua inserção no binômio Estado-Governo, seja na dimensão de identificar suas causas e finalidades, bem assim como sua gestão. Tal entendimento impõe, também, uma visão transdisciplinar, porque há de se compreender a vida financeira do Estado e sua regulação em conexão com a Economia e sua regulação, nos remetendo, portanto, ao Direito Econômico. É também da visão proposta levar em conta "a outra ponta" das Finanças Públicas, enfocando os entes Receita e Despesa, mas, sem descurar de que a Receita, precipuamente decorrente da tributação, precisa levar em conta o impacto dela na Econômica, atentando para a dimensão extrafiscal dos tributos, reconhecendo que sempre os tem, malgrado a ponderação de Eusebio Gonzales ${ }^{1}$ de que a finalidade do tributo é "arrecadação". É nesta percepção que se vai examinar o tema com a sua inserção do contexto das Finanças Públicas e, em seguida, compreender o seu regramento jurídico concernente ao Direito Financeiro.

Outro aspecto a considerar no exame que se faz do tema é o da organização do Estado. Com efeito, é de ser levado em consideração o aspecto relativo ao custeio, financiamento, gestão financeira e capacidade arrecadatória das divisões intraestatais ou internas, porquanto a Federação Brasileira se estrutura em três níveis, já que os Municípios têm estatuto constitucional que inclui competência tributária e funcional. Assim considerado, é importante levar em conta o que podemos denominar como "conjunto federativo", para abordar o tema: Dívida Pública.

Desta forma, é assim que se pensa numa abordagem com traços de sistematicidade e transdisciplinaridade.

Outro ponto referencial que se adota é o da necessidade de equilíbrio orçamentário e financeiro, resultante da necessária responsabilidade fiscal, reconhecendo desde logo que o desequilíbrio é gerador de problemas complicados, com reflexos econômicos gravosos e causador de danos sociais severos, com o que se infere contrariar a razão de ser da organização Estatal e da Ação Governativa, obrigatoriamente voltada para o bem comum, o bem geral, o bem-estar da sociedade.

Noutras palavras, a ordem financeira equilibrada, adequada e saudável, é requisito material importante para a efetivação dos Direitos Fundamentais, que vem a ser orientador principal da organização constitucional brasileira em particular, e, de certa forma, horizonte do constitucionalismo dos nossos dias.

1 Derecho Financiero y Tributário, Ed. Salmantina, s.d. 
O ponto de partida está em que o Estado não tem entre suas finalidades, objetivos, e mesmo vocação, a produção de riquezas, de bens e produtos, salvo naqueles modelos de economia estatal, já superados pela experiência histórica, ilustrando-se como exemplo o caso da China, que afirmando manter a sua formulação política e seu regime, enveredou para o campo da economia com traços do que se poderia chamar de "liberalistas", concorrendo fortemente no mercado internacional.

O Estado tem vocação e finalidades próprias. Para atender à sua vocação, demanda de uma estrutura jurídico-política destinada a instrumentalizar o exercício de suas finalidades e objetivos, estes sim, politicamente definidos, em conformidade com consensos predominantes que flutuam na sociedade, balizando as escolhas desta mesma sociedade quanto à realização e desenvolvimento de serviços públicos e de ações concretas, para as quais demanda de recursos financeiros que vai buscar na sociedade, esta fim, produtora real de riquezas, bem e serviços.

A obtenção destes recursos é feita através da arrecadação de contribuições pecuniárias impostas compulsoriamente aos indivíduos e suas instituições, estando o fundamento deste dever na solidariedade social que embasa a organização da sociedade humana e que se pode sintetizar no dever de todos e de cada um em contribuir na medida de sua capacidade para os objetivos e interesses gerais.

O funcionamento deste sistema acontece através do Governo, gizado na forma constitucionalmente estabelecida, mas, diante do quadro de desafios postos, não basta que haja governo, mas que este governo seja qualificado pela capacidade de, dirigindo o processo, produzir resultados concretos e objetivos, perceptíveis pela sociedade e pelos indivíduos, em resposta às necessidades e demandas postas através dos mecanismos de pactuação política e social. É exatamente este aspecto que vem ganhando destaque no século XXI, através da ideia de Bom Governo, entendido como probo e correto, submetido e observante da moldura jurídica estabelecida para a sua ação, mas também, eficiente na sua ação, hábil para a consecução dos objetivos e finalidades públicas.

Naturalmente que quando se cogita de "bom governo", como sendo aquele capaz de organizar as discussões e decisões e conduzir da formulação e estabelecimento de consensos sociais sobre os temas e problemas identificados dentre as demandas sociais, e, problematizando-os, formular respostas concretas para atendê-los, inclusive (e principalmente) estimando os recursos e o tempo necessário e adequado à consecução desses objetivos, estamos, muito mais buscando uma "utopia possível", do que uma realidade concreta. Cabe, inclusive, assinalar que isto tudo acontece no contexto de um processo histórico-social, sujeito às circunstâncias e injunções de toda a ordem, o que sujeita as coisas às vicissitudes conjunturais e que, não raro, aderem à estrutura delas, daí resultando o que na 
realidade se acaba por ter como o "bom governo possível", com todos os defeitos e qualidades da sociedade que o gera, levando-nos a crer serem antes características do que propriamente "defeitos e qualidades", até porque estes são mais da sociedade e é este o motivo pelo qual se projetam e se apresentam nas construções dessa mesma sociedade, como o são os governos e estrutura políticas, destacando-se serem inerentes às contradições que permeiam o conjunto.

Esta leitura no leva a recordar as palavras de Afonso Arinos de Melo Fran$\mathrm{co}^{2}$, na sua obra clássica Teoria da Constituição, de que não se pode ser otimista para não ser "pateta”, mas também não se pode ser pessimista, porque tal implica descrer do ser humano.

A linha de condução da reflexão que se desenvolve é a de que o problema tem implicações tão profundas quanto essenciais, com duas outras dimensões da vida humana: a política, quando diz respeito às escolhas e decisões inseridas no consenso construído, e a econômica, porque a relação do Estado com a economia da sociedade é inafastável, independentemente de se tem postura intervencionista, forte ou fraca, ou absenteísta, o simples fato de impor contribuições obrigatórias e de realizar despesas para desenvolver suas atividades, influi e participa da economia, nela tudo isto provocando efeitos, ora positivos, ora negativos.

Eis aí porque se entende necessária a abordagem transdisciplinar e sistêmica do tema, como afirmado ao início.

\section{VIDA FINANCEIRA DO ESTADO}

Celso Ribeiro Bastos ${ }^{3}$, estudando o tema, faz observação que contribui para o entendimento que se pretende submeter, quando diz:

A atividade financeira tem, inequivocamente, um objeto econômico na medida em que lida com recursos que têm esta natureza. No entanto, seria um grave erro identificar-se como financeira toda a atividade econômica do Estado. Há momentos em que este interfere na economia, quer regulamentado-a, quer praticando, direta ou indiretamente, atos de economicidade manifesta. Nem por isso, contudo, tornam-se eles financeiros. É necessário separar-se o Direito Econômico do Financeiro. O primeiro tem por objeto o estudo das normas que disciplinam o comportamento do Estado relativamente à economia, isto é, a disciplina jurídica da macroeconomia. O segundo disciplina a captação, guarda e dispêndio dos recursos públicos. $\mathrm{Na}$ atividade economia, propriamente dita, está sempre presente o objeto

2 Ed. Forense, RJ, s.d.

3 Curso de Direito Financeiro e Tributário, ed. Celso Bastos, SP, 2002, p. 10. 
consistente na geração de bens ou serviços, enquanto que a atividade financeira figura sempre a preocupação com o fenômeno do ingresso ou saída de recursos exclusivamente financeiros.

Temos claro que a "captação, guarda e dispêndio" de recursos produz impacto direto na Economia, seja porque retira recursos dos particulares com a captação, quanto quando ao os gerir faz despesas, remunerando mão de obra, adquirindo bens e serviços, gerando, assim, renda para os particulares, produzindo efeitos diretos na economia. Tal evidencia a impossibilidade material de "neutralidade econômica do Estado".

Resgatando-se que a atuação do Estado tem como orientador de suas atividades e ações as escolhas da sociedade, estas escolhas, seja na fixação delas mesmas, seja no processo de sua elaboração, têm natureza política porque acontecem no contexto de disputas sociais por benefícios, pactos e acordos no ajustamento delas e na construção das posições intermediárias que gerem a necessária estabilidade, fundada na concertação sobre elas, como já o percebia Aliomar Baleeiro4:

A despeito de quanto se tem escrito e discutido, não há critério rigorosamente científico para tal distinção (necessidades gerais e públicas). Em princípio, todas as necessidades públicas são coletivas, mas a recíproca está excluída, pois existem necessidades de interesse geral ou coletiva que não são necessidades públicas. A necessidade é pública quando, em determinado grupo social, costuma ser satisfeita pelo processo do serviço púbico, isto é, quando o Estado, ou outra pessoa de direito público, para satisfazê-la, institui ou mantém um regime jurídico e econômico especial propício a sua obrigatoriedade, segurança, imparcialidade, regularidade, ou continuidade a cargo de seus agentes ou por delegação a pessoas sob sua supervisão. Necessidade pública é toda aquela de interesse geral, satisfeita pelo processo de serviço público. É a intervenção do Estado para provê-la, segundo aquele regime jurídico, que lhe dá colorido inconfundível. A necessidade torna-se pública por uma decisão dos órgãos políticos.

Releva destacar a esta altura que a partir destas escolhas, que podemos chamar de qualificadas porque consensualmente escolhidas e fixadas pela estrutura e mecanismos políticos da sociedade, é que se vem a ter os elementos determinantes do volume e fluxo de recursos que a sociedade vai compulsoriamente fornecer ao Estado para a realização. É imperativo reconhecer com Edilberto Carlos Pontes Lima ${ }^{5}$ :

4 Uma Introdução à Ciência das Finanças, ed. Forense, RJ, 2012, pp. 4-5.

5 Curso de Finanças Públicas - uma abordagem contemporânea, ed. Atlas, SP, 2014, p. 5. 
Como, em vez de anjos, há apenas pessoas com interesses, falhas e, claro, algumas virtudes, o governo - ou o Estado, em termos mais gerais - é uma instituição presente em todas as sociedades, em todos os lugares. O Estado entre várias funções estabelece e faz cumprir as leis (inclusive por meio de violência) promove políticas públicas e redistribui renda. O tamanho do Estado, as áreas e em que grau ele atua é que variam ao longo do tempo e conforme o lugar. Há pessoas que defendem um a presença substancial do Estado, enquanto outras defendem participação mais modesta.

Estamos entre os que propõem examinar a questão da Dívida Pública, indo além do fenômeno em si, diversamente, se a procura entender considerando os aspectos do papel atribuído ao Estado, da forma governativa e dos instrumentos de formação das escolhas políticas que dão moldura e forma a ação estatal/governamental, reconhecendo estar nelas a sede da formulação das Finanças Públicas, tanto no que respeita aos ingressos, quanto em relação às despesas, e, daí as implicações deste processo estatal e político no processo da economia e no seu curso. Noutras palavras, há de se enfocar o tema considerando-o de forma sistêmica e interativa, tendo claro que são entes e instituições distintas, porém estreitamente relacionadas, funcionando interativamente, produzindo efeitos e influência substancial um nos outros, porquanto a Política Econômica implica em obtenção e dispêndio de recursos financeiros, e a tributação, não apenas o modelo ou tipologia dos tributos, mas a sua forma de lançamento e a gestão arrecadatória implicam em ônus adicionais aos contribuintes, onerando a atividade econômica pela ampliação dos custos “administrativos" da atividade empresarial e no ambiente de negócios, que pode favorecer ou dificultar o processo de geração, distribuição e consumo de bens e serviços, ditando o ritmo da economia. Da mesma maneira as formas, critérios e controles dos dispêndios financeiros do Estado igualmente produzem impacto no processo da economia, favorecendo-a ou servindo-lhe de empecilho.

Há, assim, sem dúvida, que se posicionar o problema da Dívida Pública, seu perfil, objetivos, causas, formas de financiamento e gestão, contextualizando-o em sua relação estreita e necessária com a economia. É o que se pretende ao longo deste estudo.

No posicionamento formulado é de ver-se que o exame das Finanças Públicas obriga que se considere a Política Financeira praticada pelo Estado no exercício das atividades que lhe correspondem porque, em relação a esta última, é forte o conteúdo político das escolhas e decisões formuladas, patenteando um aspecto que se considera relevante, qual seja, o caráter e natureza instrumental das Finanças Públicas e da Política Financeira, que desempenham o papel de viabilizar a realização das Políticas Econômicas e Sociais estabelecidas 
e executadas pelo Estado. Tal aspecto já era percebido por Aliomar Baleeiro ${ }^{6}$ que observa:

A Ciência das Finanças, entendida como disciplina ontológica, não aprova nem desaprova, não é moral nem imoral, mas amoral. Diz o que é porque é. Já a Política Financeira se inspira em objetivos morais e políticos (objetivos demográficos, higiene, nivelamento de classes, desenvolvimento, recuperação da prosperidade etc.). Estatui sobre o que deve ser e comporta uma técnica arte de como fazer, saber como fazer (know-how).” E mais adiante pontua: "Ao invez das "finanças neutras" da tradição, com seu código de omissão e parcimônia tão do gosto das opiniões individualistas, entendem hoje alguns que maiores benefícios a coletividade colherá de "finanças funcionais", isto é, a atividade financeira orientada no sentido de influir sobre a conjuntura econômica. Destarte, o setor público - a "economia pública" - não se encolhe numa vizinhança pacífica e tímida junto às lindes da economia privada. A benefício desta é que deve invadi-la, para modificá-la, como elemento compensador nos desequilíbrios cíclicos.

O Estado faz a organização política da sociedade e, através do Direito, estrutura-se para materializar esta organização, fazendo-a funcionar na busca de seus objetivos através dos mecanismos concernentes ao Governo. Ora, em assim sendo, reconhecendo que no seio da sociedade estão em permanente concorrência e disputa interesses peculiares de grupos e segmentos, naturalmente tendendo à conflitividade; temos que o papel basilar da estrutura Estado/Governo é o de arbitrar e compatibilizar as disputas, construindo pontos de convergência e concertação adequados para estabilizar o processo, mantendo, assim, a organização política da sociedade.

É exatamente desse processo que emerge a atividade financeira do Estado, que estabelece as formas de obtenção e dispêndio de recursos financeiros para dar vida aos serviços e ações destinados a atender as demandas sociais. É preciso também pontuar que esta atividade estatal de arbitrar e de movimentar os recursos tem clara natureza política porque encerra em si poder real, através do qual pode conduzir comportamentos sociais e econômicos, seja pela influência direta ou mesmo indireta.

A atividade financeira estatal não se equipara, nem em formas nem em critérios e referências, àquela desenvolvida pelo particular, principalmente porque é norteada por paradigmas consensuados e flutua entre contradições e disputas, como muito bem expõe Fonrouge ${ }^{7}$ :

6 Op. cit., pp. 33-35.

7 Derecho Financiero, Tomo I, Carlos M. Giuliani Fonrouge, ed. La Ley, Buenos Aires, 2004, pp. 2-7: "Cabe anticipar, empero, que constituyen manifestaciones fundamentales de la actividad 
Prevê-se, no entanto, que são manifestações fundamentais da atividade financeira de renda, despesas e conservação do patrimônio ou a gestão de fundos públicos e que, enquanto o meteria que desenvolve é econômica, corresponde a sujecto político um, que é o Estado e um objeto da mesma natureza. Essa ligação entre o econômico e o político oferece uma questão de discrepância; Por exemplo, alguns autores consideram a existência de dois estágios ou momentos em atividade, primeiro e segundo Econômico política, com predominância deste último, em enquanto outros, fiéis a hum conceito integral e funcional das finanças públicas, acredite. Há apenas aspectos diferentes de todo hum orgânica.

E, mais adiante pontua ${ }^{8}$ :

Possivelmente a única conclusão certa é o fracasso de todos doutrina unilateral, especialmente aqueles clássico que procurou Recolher o problema a questões puramente econômicas. A teoria política e a teoria sociológica, apesar de uma oposição conceitual básica, coincidem na necessidade de computar fatores não econômicos; Discrepâncias aparecem quando se tenta estabelecer o grau de influência que deve ser atribuído a elas, especialmente no que diz respeito aos elementos sociais e políticos.

Resta claro que todo o ciclo da atividade financeira há de estar permeado pelo conteúdo político e pela influência de elementos sociais. Este aspecto se torna mais visível e perceptível no que respeita à despesa pública, embora o mesmo ocorra no lado correspondente às receitas, valendo colacionar a observação interessante de Luiz Emigdio F. da Rosa Junior'

financiera los ingresos, los gastos y la conservación de los bienes o gestión de los dineros públicos y que se bien la meteria la cual se desarrolla es economica, corresponde a um sujecto político, que es el Estado, y a um objeto de la misma índole. Esta vinculación entre lo econômico y lo político ofrece tema de discrepância; así por ejemplo, alguno autores consideran la existência de dos estádios o momentos em la actividad, el primero político y el segundo econômico, com predomínio de este ultimo, em tanto que otros, fieles a um concepto integral y funcional de las finanzas publicas, creen que hay solo aspectos distinto de um todo organico."

8 Op. cit.: "Posiblemente la única conclusión cierta sea la insuficiencia de toda a dotrina unilateral, especialmente aquellas clasicas, que pretendian reduzir el problema a cuestiones puramente econômicas. La teoria política y la teoria sociológica, no obstante uma oposición conceptual básica, coinciden em la necessidad de computar factores no econômicos; las discrepâncias aparecen cuando se trata de estabelecer el grado deinfluencia que debe atribuiserles, especialmente em lo que respecta a los elementos social y político."

9 Manual de Direito Financeiro e Direito Tributário, ed. Renovar, RJ, 2005, pp. 27-28. 
A despesa pública produz efeitos na esfera econômica do país, e, para que se possa entender tal fenômeno deve-se partir da importância do volume das despesas em relação à renda nacional, sendo que nos Estados modernos a despesa pública exceda $30 \%$ da renda nacional. Assim, qualquer modificação nessa quantia, seja aumento ou diminuição, tem um inevitável efeito econômico. Há, no entanto, uma diferença entre os efeitos da variação da despesa pública e os da receita pública, porque nesta as consequências da variação do tributo nem sempre podem ser percebidas devido ao processo de repercussão (transferência de carga tributária do contribuinte de direito para o contribuinte de fato) e ao mecanismo dos preços, por exemplo com o ICMS e o IPI. Todavia, na despesa os efeitos da sua variação podem ser sentidos, uma vez que seu alcance pode ser facilmente determinado." E adiante arremata: "Estes efeitos econômicos da variação da despesa pública ocorrem não só na produção, como na circulação, na distribuição e no próprio consumo.

A consideração deste impacto da atividade financeira do Estado na vida econômica é essencial ponto da gestão governamental, porque atuação inepta ou desastrada, ou mesmo desviada, o que lamentavelmente frequente, causa sempre e invariavelmente efeitos desastrosos, que trazem consigo os dramas sociais do desemprego, redução de renda das famílias, queda no consumo e consequentemente da produção, perda do poder aquisitivo da moeda (inflação), que vai fatalmente desaguar na instabilidade política e social, o que a todos os títulos é indesejável.

Resta claro que o exame da vida financeira do Estado na sua amplitude impede que se dirija o enfoque apenas sob o aspecto da legalidade formal, bem diversamente, é imperativo que se considere as repercussões de tudo no mundo real, na ida ao encontro das necessidades públicas, dos direitos fundamentais e de todas as suas repercussões.

\section{DESPESA PÚBLICA, EQUILÍBRIO ORÇAMENTÁRIO E DÉFICIT}

Para a ação direcionada às finalidades e objetivos, o Estado/Governo demanda recursos financeiros para o cumprimento do que lhe cabe fazer conforme o pactuado na sociedade através de suas instâncias decisórias, obtendo os recursos através da atividade arrecadatória. Daí, acontece a etapa seguinte, que vem a ser a aplicação destes recursos, através da realização das despesas públicas, acerca da qual dilucida Aliomar Baleeiro ${ }^{10}$ :

10 Uma Introdução à Ciência das Finanças, Ed. Forense, RJ, 2010, pp. 83-84. 
Há dois conceitos para a locução “despesa pública”. Em primeiro lugar, designa o conjunto de dispêndios do Estado, ou de outra pessoa de direito público, para funcionamento dos serviços públicos. Assim, nesse sentido, a despesa é parte do orçamento, ou seja, aquela em que se encontram classificadas todas as autorizações para gastos com as várias atribuições e funções governamentais. Forma, por outras palavras, o complexo da distribuição e emprego das receitas para custeio dos diferentes setores da administração. Uma despesa pública é também, noutro conceito, a aplicação de certa quantia em dinheiro, por parte da autoridade ou agente público competente, dentro de uma autorização legislativa, para a execução de fim a cargo do governo. Envolve, em regra geral, fins de serviço público, reguladas pelo Direito Administrativo, realizados segundo a técnica da Ciência da Administração.” E mais adiante observa: “Toda despesa pública pressupõe, como elemento essencial, emprego de dinheiro para objetivos públicos. Em consequência, se o objetivo público é alcançado sem essa aplicação de dinheiro, não há despesa pública, mas outro processo financeiro e administrativo.

Não discrepa Luiz Emygdio F. da Rosa Junior ${ }^{11}$, quando examinando o tema, pronuncia-se:

Deve-se conceituar a despesa pública dos pontos de vista orçamentário e científico. A despesa pública, sob o enfoque orçamentário é "a aplicação de determinada quantia em dinheiro por parte da autoridade ou agente público competente, dentro de uma autorização legislativa, para execução de um fim a cargo do governo.

Já se observou antes que a eleição dos objetivos, as escolhas e opções derivadas dos consensos mediados pelo Estado/Governo são políticos pela sua própria natureza, porque construídos no contexto de disputas e concorrência de interesses e demandas flutuantes na sociedade, como observa Régis Fernandes de Oliveira ${ }^{12}$ :

A decisão de gastar é fundamentalmente uma decisão política. O administrador elabora um plano de ação, descreve-o no orçamento, aponta os meios disponíveis para seu atendimento e efetua o gasto. A decisão política já vem inserta no documento solene de previsão de despesas.

No mesmo sentido, Luiz Emydgio Rosa Jr., também reconhece o traço político da despesa pública, porém, visualizando no contexto do que chama de "elementos da despesa pública”, que descreve ${ }^{13}$ :

11 Manual de Direito Financeiro \& Tributário, Ed. Renovar, RJ, 2010, p. 22.

12 Curso de Direito Financeiro, Ed. RT, SP, 2015, p. 451.

13 Op. cit., p. 23. 
Os elementos da despesa pública são: a) de natureza econômica: o dispêndio, incidente em gasto para os cofres do Estado e em consumo para os beneficiados; a riqueza pública, bem econômico, representada pelo acervo originário das rendas de domínio privado do Estado e da arrecadação dos tributos; b) de natureza jurídica: a autorização legal dada pelo poder competente para a efetivação da despesa; c) de natureza política: a finalidade de satisfação da necessidade pública pelo estado, que é feita pelo processo do serviço público, como medida de sua política financeira. É universal o princípio de que a escolha do objetivo da despesa pública envolve um ato político, referente a determinação das necessidades públicas que deverão ser satisfeitas pelo processo do serviço público.

Quando se enfrenta a questão da Despesa Pública não se pode fugir da tendência natural da sua expansividade, da sua tendência de crescimento progressivo. Vários são os elementos motivadores deste fenômeno, como o crescimento demográfico, o surgimento de novas necessidades públicas relativas a bens e serviços daí decorrentes, incorporação tecnológica à vida cotidiana, surgimento de demandas novas pela ampliação do espectro dos direitos fundamentais, emergências circunstanciais mais frequentes, pressões internacionais, políticas de intervenção estatal na economia, ampliação da estrutura de prestação de serviços públicos, necessidades de atuação financeira nos mercados, dentre outros. Bem se vê que o que podemos denominar de elementos pressionadores da expansão das despesas são gigantescos, o que torna sempre delicado e difícil tanto arbitrar demandas e necessidades, como formular respostas adequadas, necessárias e viáveis para elas, dentro do universo finito das riquezas, que é fator limitante à capacidade da sociedade de suportar custos.

Neste ponto é importante rememorar-se a lição de Gaston Jèze ${ }^{14}$ que em sua classificação de despesas, especialmente quando trata das despesas produtivas e improdutivas, das úteis e das inúteis, apontando como produtivas e úteis as que geram receitas pelo uso e funcionamento, e, contrariamente, as que não geram receitas, são inúteis e improdutivas. Exemplificando as primeiras como a construção de portos e ferrovias, e, as segundas despesas de guerras, assistência e de infraestrutura sem pagamento pelo uso, mas observa que algumas despesas não improdutivas no presente, porém, mais tarde se podem revelar úteis.

Neste sentido Louis Trotabas ${ }^{15}$ observa que as despesas públicas são de utilidade pública quando realizadas com finalidade pública e através dos serviços

${ }^{14}$ Cours Élémentaires de Science dês Finances et de Législation Fianciére Française, Ed. La Memoires Du Droit, Paris, 2010, p. 113.

15 Precis de Science et Legislatión Financieres, Ed. Dalloz, Parias, 1938, p. 12. 
públicos, regrada pelo Direito Administrativo, devendo ser observado que os elementos informadores deste critério são variáveis no tempo nas circunstâncias, e, assim, as despesas flutuam conforme a variabilidade destas mesmas circunstâncias.

Tais considerações nos levam a considerar o que se denominou de qualidade da despesa, que significa que a despesa há de ser produtiva, avaliados constantemente seus resultados e efeitos, desta avaliação há de decorrer ajustes e adequações maiores ou menores, conforme os resultados obtidos, tudo pautado pela racionalidade, o que pressupõe grau razoável de planejamento e articulação adequada entre fins e meios, custo/benefício, portanto, a capacidade real e efetiva de responder com eficácia ao pretendido. Entende-se que é este quadro que legitima o exercício do poder financeiro/tributário do Estado, e substancia a solidariedade social justificadora da contribuição da cidadania via tributos, inclusive quando necessário aumento de sacrifício pela eventual elevação da carga tributária. Diversamente, cresce a resistência à contribuição, com a sensação de insatisfação decorrente da "inutilidade do esforço", levando a sonegação e omissão no seio da sociedade.

Neste ponto, é de ver-se que ao tratar do tema é imperioso compatibilizar dois aspectos importantes, de um lado a pressão expansiva, contraposto a outro, da limitação real da sociedade de suportar e fazer face à cobertura de tais necessidades. Este é ponto de atrito e até mesmo de conflito político interno nas sociedades contemporâneas, porque a expansão da despesa implica na necessidade de aumento da receita e, consequentemente, no aumento da tributação, onerando a vida dos indivíduos, famílias e empresas.

É importante destacar a importância que se reputa fundamental da existência de equilíbrio entre demandas e capacidade de suportar. Antes se referiu que os tributos, fonte principal das receitas públicas, têm efeito extrafiscal, impactando na economia, isto porque a capacidade contributiva dos indivíduos, das famílias e empresas, em nosso ver, tem o limite intransponível do mínimo vital/existencial, significando que a vedação constitucional da tributação confiscatória é, antes de tudo, realidade econômica, exatamente porque vulnera este mínimo. A propósito, o comprometimento da renda privada com a tributação traz dois inconvenientes relevantes, a redução da capacidade de consumo, que afeta a produção, emprego, renda e arrecadação, porque é o consumo que sustenta o sistema, e, também, com igual gravidade, a capacidade de poupança e investimento, que obstaculiza o crescimento da economia e o seu fluxo normal.

O grande velocino de ouro dos nossos dias é a busca exatamente por este equilíbrio, consideradas as enormes dificuldades e problemas advindos do desequilíbrio, mormente se ocorrente durante lapso temporal significativo. 
O crescimento das despesas é apontado por Baleeiro ${ }^{16}$ quando diz:

A ascensão invariável, malgrado a diversidade das circunstâncias, foi reconhecido como uma tendência invencível não só na época moderno, mas até de períodos anteriores, segundo investigações históricas, designando-as os financistas como o "fenômeno do aumento progressivo das despesas públicas.

Porém, o mesmo autor adverte que ${ }^{17}$ :

(...) impõe-se, pois, tanto quanto possível, distinguir o aumento aparente do aumento real das despesas públicas. Importa inicialmente a compreensão de que, no caso, há a verificar se determinado grupo político - Estado soberano, província ou município - suporta gravame maior do que anteriormente, em proporção à sua área geográfica e população, para a satisfação de necessidades consideradas públicas. Não basta comparar o balanço ou a prestação de contas da execução orçamentária, no curso de um século ou de um quarto de século, para afirmar-se que decuplicaram as despesas ou mesmo que o custo per capita dos serviços públicos se multiplicou. A comparação há de ser feita com base na renda nacional.

O citado autor aponta como sendo causas ilusórias do aumento das despesas públicas: a desvalorização da moeda, sistema de contabilidade pública pelo bruto em substituição a sistemas que contemplavam apenas o líquido das receitas, crescimento da população, acréscimo de territórios e transferências de atividades privadas para o serviço público. E, mais adiante, aponta como causas do crescimento real da despesa ${ }^{18}$ :

Descontadas as aparências, a realidade confirma o crescimento ininterrupto das despesas públicas no sentido de que, em cada Estado, ou mesmo dentro de cada grupo político menor - Estado-Membro ou Município -, é crescente a fração que de suas rendas os indivíduos reservam para satisfação de novas necessidades públicas ou, paralelamente, a extensão e a ampliação da rede de serviços públicos a maiores superfícies geográficas e humanas.

Devem ser responsabilizadas pela parte mais considerável do aumento progressivo:

a) o incremento da capacidade econômica do homem contemporâneo, sobretudo devido ao aperfeiçoamento da técnica de produção e, portanto, da produtividade;

\footnotetext{
16 Op. cit., p. 99.

17 Op. cit., p. 101.

18 Op. cit., loc. cit.
} 
b) a elevação do nível político, moral e cultural das massas sob o influxo de ideias-forças, que levam os indivíduos a exigir e a conceder mais ampla e eficaz expansão dos serviços públicos;

c) as guerras, que de lutas entre grupos armados, restritos, assumiram o caráter de aplicação total das forças econômicas e morais, humanas, enfim, do país na sorte do conflito: a "guerra total” das gerações contemporâneas. Essas três causas principais não só exercem ações e reações recíprocas para o mesmo efeito, mas enfeixam vários outros fatos derivados e conexos.

Dois aspectos da observação de Baleeiro merecem destaque a nosso ver, a primeira delas é de que fatores econômicos, como aumento da produção, incorporação tecnológica e qualificação de mão de obra, que se pode gizar como sendo aumento da produtividade econômica, contribuem para aumentar a capacidade contributiva e, consequentemente, a capacidade de suportar o incremento das despesas. O segundo, o reconhecimento da existência de uma dinamicidade no processo, excluindo, desde logo, a concepção estática do sistema. Isto significa dizer que a vida da economia tem altos e baixos, aumentos e diminuições, oscilações, e, para todo este quadro complexo, há de haver ajustes e adequações, daí a incorporação de tecnologia de gestão e governança com forte conteúdo técnico, para fazer face às vicissitudes próprias da vida, tanto da sociedade, quanto do Estado, porque o processo econômico tem épocas de expansão e crescimento, épocas de estagnação e épocas de recessão. Em todas as hipóteses aventadas há demanda de políticas públicas adequadas, mesmo se reconhecendo, como o faz o autor citado, a possibilidade real de enriquecimento da sociedade ${ }^{19}$ :

Enfim, a maior riqueza do homem contemporâneo possibilitou margem maior de dinheiro para os serviços públicos, que se fizerem indispensáveis ou, pelo menos, foram desejados em face das novas circunstâncias. Não só a tributação encontrou campo mais vasto, senão também o crédito público, pelas largas disponibilidades dos mercados de capitais, que nem sempre encontram ou preferem investimentos privados.

A realização das despesas públicas, é de se destacar, precisa considerar dois aspectos importantes, o primeiro é que as opções políticas formuladas, as escolhas feitas, materializam-se em linhas gerais estabelecidas pelas instâncias decisórias da organização política, geralmente a representação popular que é o Parlamento; mas, ainda assim, eis o segundo, há um espaço discricionário atribuído ao Governo, Poder Executivo de efetuar escolhas no que respeita a forma e tempo de

19 Op. cit., p. 105. 
concretização, assumindo a responsabilidade política, pelas decisões e atos, como adverte Marcus Abraham ${ }^{20}$ :

Importante ressalvar que, apesar de estas prioridades e parâmetros que conduzem o processo decisório das despesas públicas decorrerem de previsões constitucionais, sempre haverá um campo deliberativo para a sua realização, a ser definido e executado pelo administrador público.

As escolhas e opções precisam cingir-se às circunstâncias e limitações materiais, isto é aterem-se às limitações e contingencialidades materiais. É exatamente a busca pelo equilíbrio orçamentário que vem a consistir em síntese como a compatibilidade entre receita e despesa, ajustando os dispêndios às disponibilidades de recursos. É interessante a lição de José Marcos Domingues ${ }^{21}$ :

Ora, orçamento supõe planejamento, que tem um aspecto restrospectivo de exame de desempenho passado da economia (seus indicadores e capacidade de produção de receita ao estado) e outro prospectivo de avaliação das necessidades a serem atendidas pelos serviços públicos no exercício futuro; busca-se atender ao princípio do equilíbrio orçamentário, ultrapassada a visão clássica do equilíbrio meramente financeiro entre receitas e despesas, mas no sentido de equilíbrio moderno e contemporâneo, macro econômico, que um saudável programa de incentivos à produção e ao consumo pode agregar esforço em prol do pleno emprego e do combate à recessão, sem descurar do controle da inflação, que em espiral ascendente pode significar a derrota do planejamento exigido pela Constituição. Equilíbrio orçamentário é princípio que vai muito além de uma preocupação aritmética ou projeções financeiras, significando a contenção do poder de tributar em coordenação com a capacidade contributiva da sociedade em busca de um gasto público responsável e saudável na medida em que catalisa, via orçamento, a carga tributária em favor do adequado financiamento de políticas públicas que retornem em serviços públicos de qualidade o sacrifício fiscal em prol do bem comum.

É fulcral que se destaque, nesta concepção moderna de equilíbrio orçamentária, o que se considera ser a qualidade das despesas. Não basta que sejam previstas e realizadas na mais estrita legalidade (formal), há que ser essencialmente eficientes, isto é capazes de alcançar objetivos e propósitos claros, objetivos e

20 Curso de Direito Financeiro Brasileiro, Ed. Elsevier, 2010, p. 155.

21 Equilíbrio orçamentário vai muito além da projeção financeira, Consultor Jurídico, 10/12/14, (https://www.conjur.com.br/2014-dez-10/jose-domingues-equilibrio-orcamentario-projecao-financeira). 
trazer resultados concretos em benefício da sociedade, seja direta ou indiretamente, o que implica em permanente avaliação da relação despesas/resultados efetivos, com a implementação de correções e ajustes imediatos em busca de efeitos positivos concretos. Tem-se claro, neste enfoque, que a despesa pública realizada, ainda que formalmente lícita, pode ser improdutiva, estéril mesmo, consubstanciando desperdício de recursos, o que a nosso ver constitui ilicitude financeira.

Tem-se como existente o princípio do equilíbrio orçamentário como decorrente do contido no art. 167, inc. III da Constituição, que embasa o art. $4^{\circ}$, inc. I, "a" da Lei de Responsabilidade Fiscal, impondo a compatibilização de dispêndios com as capacidades arrecadatória e contributiva, igualando os montantes de receita e despesa, porém, esta rigidez absoluta não apenas nem sempre é possível diante de circunstâncias adversas, porque enseja a paralisação da ação estatal/ governamental diante destas mesmas circunstâncias. Isto significa dizer que se deve compreender a ocorrência de déficit orçamentário, pelo menos como exceção, e que isto não é o fim do mundo. A questão é como gerir, administrar, enfim, tratar deste déficit, não apenas mantendo-o sob controle rigoroso, bem como atuando para sua progressiva redução. Isto também tem conteúdo político, por implicar em escolhas quase nunca fáceis.

Ferreira Lapaza ${ }^{22}$ observa que a Fazenda Pública consagrou o princípio do equilíbrio orçamentário como política correta, estabelecendo-se que as despesas ordinárias sejam cobertas com as receitas ordinárias, encerrando-se as contas em equilíbrio. Entendendo-se que os déficits com emissão (criação) de Dívida Pública são indesejáveis, como também o são os superávits, por implicarem em injusta transferência de recursos da economia privada para o Estado. Prossegue observando que a contraposição está na constatação entre o estado liberal e o estado intervencionista, sendo que o primeiro deve interferir minimamente na economia para não perturbá-la, e, o segundo, pretende ser o principal responsável pelo processo econômico, assim, os gastos públicos não são "um mal necessário" que se deva reduzir ao mínimo, porque são ferramentas para as transformações necessárias na sociedade.

E pontua ${ }^{23}$ :

${ }^{22}$ José Juan Fernando Lapaza, Instituciones de Derecho Financiero, Ed. Marcial Pons, Madrid, 2010, pp. 153-155.

${ }^{23}$ Op. cit. loc.: "Pero los últimos lustros han visto reintroducir el principio del equilíbrio presupuestario em el centro de la política econômica, dentro del mas amplio debate sobre el papel del Estado em la economia y em la sociedad. El exceso em la acción del Estado em el mantenimiento a toda costa de um determinado nível de demanda de bienes y servicios, se dice em este sentido, puede difcultar, em épocas de recesión,um descenso del nível de precios y, dentro de el, 
Mas as últimas décadas viram a reintrodução do princípio do equilíbrio orçamentário no centro da política econômica, no debate mais amplo sobre o papel do Estado na economia e na sociedade. O excesso na ação do Estado na manutenção a qualquer custo de um determinado nível de demanda por bens e serviços, diz-se nesse sentido, pode dificultar, em tempos de recessão, a queda do nível de preços e, dentro dele, uma diminuição nas taxas de juros necessárias para uma recuperação do equilíbrio do sistema devido aos pontos fortes do mercado.

E, mais adiante arremata ${ }^{24}$.

Mas o debate em torno dele não pode ser considerado, absolutamente, fechado. Por outro lado, a fase de recessão econômica iniciada em 2007-2008 e as políticas anticíclicas desenvolvidas pelos estados da União (no âmbito de uma ação globalizada) destacaram, mais uma vez, que o equilíbrio orçamentário não deve ser entendido como É um dogma indiscutível, mas que deve ser sempre considerado como um ponto de referência obrigatório na ação de um Estado que, necessariamente, deve assumir um papel decisivo na economia.

É de se ver também que, quando se cogita de equilíbrio das contas públicas, é imperioso considerar o Estado na sua totalidade, significando levar em conta a situação das unidades infranacionais ou subnacionais que compõem o Estado, no caso brasileiro, os Estados e Municípios, portanto, considerando que estes dispõem de Orçamentos, há de se considerar o equilíbrio destes, também.

Ora, na ocorrência do desencontro entre Receita e Despesa, quando esta supera àquela, a alternativa é a constituição de dívida, porque o Estado vai ao mercado de capitais ou de crédito, obtém recursos de forma onerosa, remunerando capital e, com este valor, cobre a diferença, fazendo incluir uma despesa adicional, vinculada ao custeio do serviço e à amortização desta dívida. Isto significa que a gestão ou administração desta dívida implica, a seu turno, em mantê-la em níveis compatíveis com a realidade econômico-financeira espelhada no Produto Interno Bruto, seu ritmo de crescimento ou não, garantindo a solvência clara e

um descenso de los tipos de inteŕres necesario para uma recuperación del equilíbrio delsistema por las próprias forzas del mercado".

${ }^{24}$ Op. cit. loc.: "Pero el debate em torno a El no puede consdierarse, em absoluto, cerrado. Por el contrario la fase de recesión econômica iniciada en 2007-2008 y las políticas anticíclicas desarrolladdas por los Estados de la unión (em el marco de uma acción globallizada) han puesto de relieve, uma vez más, que el equilibrio presupuestario no há de entenderse como um dogma indiscutible, pero que há de considerarse siempre como um punto de referencia obligado em la acción de um Estado que, necesariamente debe assumir um papel decisivo em la economia”. 
confiável do sistema, vez que rompido este limite, a tendência natural é o agravamento do quadro, que pode levar à paralisia completa ou mesmo ao colapso da máquina estatal e dos serviços públicos.

Exatamente em fidelidade ao enfoque que se dá ao tema, fazemos neste breve estudo algumas reflexões sobre o controvertido tema da Dívida Pública, tendo como pano de fundo a Federação, abordando as questões do sistema de gestão e controle financeiro do Estado Nacional (União) e, articuladamente, as relações com e entre os entes Federativos, Estados membros e Municípios. No caso brasileiro, a federação é tridimensional, temos, assim, três polos de poder político em exercício, repartição, portanto, de competências e atribuições entre as três dimensões, sendo perceptível a heterogeneidade entre os entes que compõem a federação, sua capacidade econômica e consequentemente arrecadatória, e suas atribuições e necessidades, e as políticas de redistribuição de riqueza inter-regional, mercê de disposição constitucional. O dilema se põe com a necessidade de compatibilização entre o controle indispensável da gestão financeira e sua regulação jurídica, e a autonomia dos entes federados.

É significativo o debate sobre o equilíbrio orçamentário, com posições díspares. Umas defendendo o chamado modelo da austeridade ortodoxa, onde é abominada a ideia de déficit, centrando-se em que somente seja feito o dispêndio do arrecadado, que sintetizam no "só se gasta o que se tem". Outras, ao contrário, sustentando que a existência do déficit, a decalagem entre o arrecadado e disponível e os dispêndios, pode ser tolerada como necessária e útil em determinadas circunstâncias, inclusive para impulsionar o crescimento econômico.

A divergência em nosso ver não tem vencedor absoluto.

Nem o "descontrole" das finanças públicas, com a chamada "gastança" sem limites, ou o descuido leniente; nem a rigidez do orçamento zero. A aurea mediocritate está na relativização dos dois extremos, e o centro fundante desta relativização está na necessária e indispensável adequação às circunstâncias, na consideração aos dados conjunturais da economia, nas necessidades reais de desenvolver políticas anticíclicas, de realizar investimentos estratégicos para o curso adequado da economia, das demandas indispensáveis de expansão de crédito, mesmo das realizações de políticas sociais inclusivas de redistribuição de rendas.

Sem que se entre na discussão profunda por escapar ao objeto do estudo, a função política do estado é o de intermediar os interesses, demandas e conflitos, administrar as contradições, que são inerentes à vida social. Tal acomodação de contrários e diferentes é que torna possível a estabilidade indispensável à vida social e, consequentemente, à busca e construção do bem comum. Com as estruturas estatais vem a atuação governamental, delas se utilizando para o desenvolvimento das relações sociais e econômicas ínsitas na vida social. 
O Estado, que é a estrutura para o exercício do poder político no contexto social, por óbvio desenvolve atividade financeira, tendo, assim, vida financeira, que em apertada síntese consiste em arrecadar recursos compulsoriamente e despendê-los conforme o interesse público politicamente definido. Com razão Álvaro Rodriguez Bereijo ${ }^{25}$ em estudo preliminar sobre o Direito Orçamentário de Paul Laband, que, fazendo a intersecção financeiro/constitucional/político/administrativo, a identifica na Lei Orçamentária com caráter de diretriz política e ato de controle da vida financeira, tendo como pressuposto a coparticipação do parlamento e do governo, no que viabiliza um plano de ação de governo. Ora bem, este plano de ação de governo pode, e o mais das vezes acontece, demandar, circunstancialmente, maior volume de recursos do que aqueles disponíveis via arrecadatória ordinária.

É evidente que esta visão em nenhum momento exclui o critério e o paradigma da qualidade da gestão fiscal da administração financeira (governança) do Estado e seu aparato.

Ora, nessas ocasiões não resta senão recorrer ao crédito, gerindo o estoque de dívida pública, para a obtenção dos recursos necessários a enfrentar os dispêndios. Neste aspecto não é excesso referir que as escolhas políticas das destinações de recursos originadores da despesa superior (circunstancialmente) à arrecadação sejam consensuais, reconhecidas para serem legitimadas e estabelecidas de forma clara e transparente, com critérios e referências nítidas e precisas.

A ocorrência do déficit que se entende deve ser prevista, identificada e principalmente quantificada o quanto possível, pode ser coberta com endividamento, desde que também prevista a reposição (pagamento) da dívida, seu serviço, e considerado o impacto dos recursos no processo econômico, considerando-se que os gastos públicos têm significado no processo da economia.

E tudo isto precisa se harmonizar com a organização estrutural do Estado, o que é deveras complexo em decorrência das competências e autonomias que lhe são inerentes. Por isto mesmo, ainda que ligeiramente seja necessária a compreensão da Federação como ente político, como o acentua Machado Horta ${ }^{26}$, nas singularidades e complexidades de sua estrutura, e razão assiste ao Mestre quando a qualifica como:

(...) criação jurídico-política e pressupõe na sua origem e existência uma constituição federal, para instituí-la”, arrematando ainda com a afirmação

25 Laband, Paul. Derecho Presupuestário. Ed. Tecnos, Madrid, 2012.

${ }^{26}$ Estado Federal e Tendências do Federalismo contemporâneo, Machado Horta, Raul. Direito Constitucional. Ed. Del Rey, BH, 2010. 
de que existe relação de causalidade entre a Constituição Federal e o Estado Federal.

A federação, pois, deriva de um pacto político maior, integrando a organização política do Estado Nacional, como observa ainda o autor citado ao referir o caso brasileiro ${ }^{27}$ :

No federalismo brasileiro, identificamos (imputação normativa mediante criação jurídica dos Estados no documento de fundação do Estado Federal) o segundo processo (antes referido) de criação do Estado Federal, quando a associação normativa dos Estados, operada pela Constituição, gerou o simultâneo nascimento da união e dos estados componentes, que passam a integrar a República Federativa.

É conveniente fixar desde logo que o chamado poder derivado dos Estados membros da Federação brasileira precisa ser compreendido como poder constituído, porquanto existe e haure sua força, inclusive político-normativa, na Constituição Federal, até porque, como bem observou o Mestre Horta, deu-se imputação jurídica, o poder político e jurídico do Estado Unitário original transferiu (ao imputar) parcela definida e limitada deste poder político-jurídico para os Estados membros, e, posteriormente, na formulação constitucional de 1988, outras parcelas, também definidas e limitadas, paras os Municípios, fazendo a articulação do conjunto na repartição de competências e de rendas.

É importante deixar claro que diante disto, a autonomia dos Estados e mesmo dos Municípios deve ser entendida e mensurada considerando-se a imputação jurídica havida (caráter constituído) quando da formação primeira da Federação brasileira, com o que a conclusão necessária a respeito, tem-se significativo grau de supremacia da União sobre os entes federados.

É neste contexto que se insere o que podemos entender como sendo a autonomia de assumir endividamento que toca aos Estados Membros e Municípios, sujeita às limitações e regramento da União, identificando-se neste regramento e controle, com estabelecimento de limitações e macrorregulação, a consequência da imputação jurídica antes referida (poder transferido), o que nos leva a considerar tal arcabouço jurídico como sendo parte da imputação, como parte do amoldamento da autonomia, o que o legitima política e juridicamente.

A tensão que se estabelece, portanto, é entre a capacidade de, parcialmente, dirigir seus destinos, e, doutro lado, manter-se inserido no contexto geral do estado nacional, sem construir conflitos internos neste conjunto do qual faz parte.

27 Op. cit. 
Completa o quadro a construção pretoriana (oriunda do STF) do princípio da simetria, que é necessária para a manutenção harmônica do sistema federativo, marcado pelo conjunto de normas obrigatórias de organização e funcionamento dos entes federativos, que vem a ser o que Orlando Bitar $^{28}$ chamou de "mínimo federativo" ou "eixo da federação", mas, é conveniente a advertência ponderada de André Ramos Tavares ${ }^{29}$ de que:

Admitir esta suposta obrigação geral de simetria, não pode significar a redução ou eliminação de autonomia, que é constitucionalmente reconhecida de maneira expressa. Ou seja, a simetria não pode sobrepor-se à autonomia.

A simetria cogitada, a articulação necessária dos entes federativos, a observância referencial da relação unidade/conjunto, as referências relativas ao Estado-nacional, tudo isto precisa ser considerado sem que se perca de vista a autonomia essencial dos Estados-membros da Federação e dos Municípios, que entre nós são entes federativos, dotados, inclusive, de estatuto constitucional. A questão que se põe é: como tratar do necessário estabelecimento do déficit/dívida, e da renúncia fiscal pelos entes federativos, cuja necessidade de controle e limitação é indiscutível, sem que isto se configure em captis diminutio dos Estados e Municípios.

A autonomia entendida como a competência constitucional (atribuída) de auto-organização e autogoverno envolve necessariamente a existência de vida financeira própria, voltada, por óbvio, aos interesses e dimensões do âmbito da competência pertinente, e, entende-se que, neste âmbito, a autonomia não pode ser restringida sem vulneração da autonomia.

\section{DÉFICIT E DÍVIDA PÚBLICA}

Como vimos observando, a ocorrência do déficit está integrada às vicissitudes da vida financeira e econômica do Estado e da Sociedade, envolvido em pressões internas e externas, circunstâncias e condições previsíveis e imprevisíveis. Neste quadro, para suprir o déficit, o Estado recorre ao crédito, indo em busca de recursos na economia privada, nacional ou estrangeira.

Noutras palavras, supre o déficit através da formação de dívida, da dívida pública. Esta, a seu turno, enseja duas necessidades financeiras relevantes, a primeira é o serviço da dívida, que consiste no pagamento dos juros e custos dela, e, a segunda, a amortização, para quitá-la. Ambas as necessidades hão de estar claramente inseridas na Política Econômica e Financeira do Estado para que

\footnotetext{
28 Estudos de Direito Constitucional, ed. Renovar, RJ, 2008.

29 Curso de Direito Constitucional, ed. Saraiva, 2010, SP, p. 1109.
} 
mantenha o controle da situação. No quadro é pertinente a consideração feita por Jean-Luc Albert e Luc Saidj ${ }^{30}$ :

Estes soam mais eficazes e mais críticos. É verdade que eles foram, ou ainda podem constituir, um instrumento político e econômico, e fornecem ao público os meios para assegurar uma considerável missão econômica e social. Em particular, a própria concepção clássica admite, ou até exige, que o equipamento seja financiado pelo empréstimo porque, ela explica, eles beneficiam as gerações futuras, que devem ser logicamente suportadas pelo peso da rebelião nos noptera, bem como, no quadro do controle financeiro público dos estados, a Comissão Europeia deve examinar "se o défice público excede o défice de investimento público". Mas o caráter quase permanente e a extensão desses déficits acabaram tendo efeitos econômicos negativos: por um lado, é necessário financiá-los, o que leva a grandes empréstimos públicos que têm "efeito positivo" sobre empresas, que as privam de capitais necessários ao investimento e contribuem para o aumento das taxas de juros (mesmo quando não são financiadas pela criação monetária); Por outro lado, esses déficits resultaram em um grande ônus da dívida pública, que se tornou mais sobrecarregada com orçamentos públicos, começando pelos interesses a serem atendidos que, especialmente durante a crise econômica, estão afetando cada vez mais a economia. ... déficit (fenômeno autoalimentador da dívida).

Para examinar a questão proposta se estabelece a relação entre déficit, endividamento e renúncia fiscal, eis que tem em comum o elemento de dispêndio de recursos, seja pelos gastos mesmo, seja, em última hipótese, pela não arrecadação.

30 Finances Publiques, Dalloz, Paris, 2011, p. 233: “Ceux-ci son de em effet plus em plus critiques. Certes, ils ont pu ou peuvent encore constituer um instrument politique conjoncturelle ET fournir aux povoir publics um moyen d'assurer de mission économiques ET sociales considerable em attenuent Le recours aux prélévents obligatoires; em particulier la concepcition classique elle-même admet, voire exige, que les équipaments soient financés par l'emprunt car, expose-t-elle, ils béneficient aux génerations futures que doivente donc logiquement supporter le poids du rebourcement - on notera ainsi que, dans Le cadre de la surveillance dês finances publiques dês États, la Comission européenne doit examiner "si Le déficit publique excede les despeses publiques d'investissements". Mais Le caracteres quasiment permanent et l'ampleur de ces déficits ont fini par entraît dês effects économiques néfasts: d'une part, Il faut les financier, ce qui conduit à d'importants emprunt publics qui ont um "éffect d'éviction" sur les entreprises puisquiłils privent ces dernières de capitoux nécessaires à l'investissemen et contribuent à une hausse dês taux d'intérêt (même quand ils NE sont pás financés par création monetaire); d'autre part, ces déficits ont fini par entraîner um important endettement public qu epése de pus em plus lourdment sur les budgets publics, à commencer par les intérêts à servir qui, sourtout em période de récession économique, contriuent de plus em plus au....déficit (phénoèmne d'autoalimentation de la dette). 
No contexto da política econômica desenvolvida pelo Estado através do Governo, pode ocorrer, e não é raro que aconteça, a superação das receitas pelos gastos, e a cobertura desta superação dá-se pelo endividamento. A questão principal não é o endividamento, mas sua dimensão, prazo, custo, previsão expressa de superação.

Não se considera, para os fins da reflexão que se faz, a dívida flutuante, coberta pela emissão de títulos resgatáveis no mesmo exercício, que funciona como antecipação de receita (certa e definida), desempenhando mais mecanismo de fluxo de caixa, medida de tesouraria, do que propriamente decisão de endividamento.

Centramos a atenção na dívida pública constituída a partir da emissão de títulos públicos no mercado financeiro e na contração de empréstimos com instituições financeiras. Nas duas hipóteses vislumbramos a constituição de dívida significativa, onerosa, cujo peso no Orçamento deve ser levado seriamente em consideração, sob pena de termos a retroalimentação da dívida, como advertem os autores antes citados.

A equação se nos apresenta como: constituição de dívida para a cobertura de déficit, oneração orçamentária com a dívida, necessidade de medidas concretas de redução do déficit e também da dívida. Com efeito, mantidos déficit e dívida, a tendência é a expansão de ambos ao longo do tempo, consumindo progressivamente as disponibilidades orçamentárias, implicando na redução da capacidade operacional e de custeio da máquina estatal, incapacitando-a, inclusive e especialmente para enfrentar a evolução vegetativa e a perda da capacidade de investimento público.

Quando se considera o problema na sua globalidade, incluindo déficit e endividamento dos entes federativos, a questão posta evidencia a necessidade de um equilíbrio que se pode considerar difícil. Se de um lado as contas nacionais atinentes ao Estado nacional e, portanto, ao conjunto e suas partes, quase que impõe grau de uniformidade, de outro, o atributo de autogoverno implica na existência de relativo grau de escolhas políticas e ações governamentais, que pode eventualmente colidir, porquanto nem sempre os interesses coincidem, nem sempre as referências de conveniência e oportunidade se articulam.

Não é excesso colacionar a esclarecida posição de Roque Antonio Carrazza ${ }^{31}$, quando fixa que:

(...) princípio federativo - verdadeira coluna mestra do nosso sistema jurídico -, convivem harmonicamente (e nisto estamos com Kelsen) a ordem jurídica global (o Estado Brasileiro) e as ordens parciais, central (a União) e periféricas (os Estados-membros). Esta múltipla incidência só é possível por

31 Direito Constitucional Tributário, ed. Malheiros, 2013. 
força da cuidados discriminação de competências, levada a efeito pela Constituição da República.” E extraindo as consequências desta convivência harmônica, insere na autonomia do Estado-membros a gestão financeira, que se pode considerar como sendo vida financeira própria, pontuando: "Parece certo que, sendo autônomo, cada Estado deve, sem interferências federais ou estadias, prover as necessidades de seu governo e administração. Para isto, a Lei Maior conferiu a todos o direito de regular suas despesas e, conseguintemente, de instituir e arrecadar, em caráter privativo e exclusivo, os tributos que as atender.

Quer nos parecer importante divisar um caminho capaz de harmonizar as naturais discrepâncias, compatibilizar as disputas de interesses, acomodando dentro do possível as diferenças, porém sem desatendê-las. E, neste particular, o arsenal do Direito Financeiro pode e, mais do que isto, precisa contribuir considerada a sua inserção no contexto do Estado de Direito, destacada a constituição financeira que se incorpora à organização, tanto do estado, quanto do governo, no horizonte da incorporação da cidadania e dos direitos fundamentais.

O que motiva a reflexão que ora se faz é o sistema da dívida pública considerada a organização complexa do Estado Federal, onde existe orçamento do estado nacional, dos estados membros da federação e, no caso brasileiro, dos municípios. Tem-se um quadro extremamente complexo. Como tal, há de ser examinado tanto no conjunto, como em cada uma das duas partes, destacando as relações e ligações essenciais entre elas, especialmente porque há de se fazer a articulação entre as autonomias correspondentes às partes e ao todo, bem assim como o pacto constitucional estabelecido para a organização do sistema.

Temos, assim, um quadro da dívida nacional formado pelo endividamento da União, pelos Estados membros, individualmente considerados e no seu conjunto, e da mesma forma, o dos municípios, residindo à complexidade nas limitações da ordem jurídica no controle recíproco dos subsistemas referidos e do conjunto sobre as partes, porquanto se é fato que precisa existir e ter certa rigidez, o é também, simultaneamente, flexibilidade para que não sejam atingidas as autonomias.

É sem dúvida uma questão a ser enfrentada, porque o equilíbrio saudável das contas públicas é de interesse direto e imediato de todos e de cada um, não podendo, assim, ser descurado ou omitido.

É importante fixar um conceito claro e objetivo de dívida pública, acerca do qual pontua Régis de Oliveira ${ }^{32}$ consiste em “assunção de débito voluntariamente", que se esclarece com Ricardo Lobo Torres ${ }^{33}$ :

32 Curso, p. 5-8.

33 Curso, p. 219. 
abrange os empréstimos captados no mercado financeiro interno ou externo, através de contratos assinados com bancos e instituições financeiras ou do oferecimento de títulos ao público em geral, [entendidos, aí também] a concessão de garantias e avais, que potencialmente podem gerar endividamento.

Na mesma linha, Luis María Cazorla Prieto ${ }^{34}$ remetendo ao conceito legal (Ley 47/2003, artigo 92) observa que constitui a modalidade principal do gênero de operações de crédito dos entes públicos referindo que:

O Estado constitui o conjunto de capitais emprestados pelo Estado através de uma missão pública, acordo de operações de crédito, sub-rogação na posição devedora de um terceiro e, em geral, através de qualquer outra operação financeira do Estado, destinada a financiar as despesas do Estado para financiar as despesas do Estado ou para constituir posições de tesouraria ativas.

Constituindo objeto daquilo que Luque Mateo e Aguilar Rubio ${ }^{35}$ atribuindo estatuto próprio, identificam ser objeto do "Derecho Del Crédito o del envidamento Público", e que consiste: "nos capitais tomados por empréstimo pelo Estado ou seus organismos autônomos".

No Brasil, temos também conceito legal estabelecido no artigo 29 da Lei n. 102 de 04 de maio de 2000, tal como acentua Ives Gandra da Silva Martins ${ }^{36}$ comentando o dispositivo:

Diante do conceito posto entende-se conveniente rememorar que em se tratando de crédito, considerado o sentido estrito adotado, que o elemento central é a confiança, da qual decorre a aplicabilidade do princípio da boa-fé, como observa Régis Oliveira em seu magistério sobre o tema.

Exatamente em prestígio e defesa do princípio da boa-fé, da fiabilidade do Estado e dos seus atos é que a Dívida Pública e Operação de Crédito mere-

${ }^{34}$ Derecho Financiero y Tributario, Thomson Aranzadi, Navarra, 2007, p. 620: "Constituye la denda Del Estado el conjunto de capitales tomados a prestamos por el Estado mediante a missiónpública, concertación de poeraciones de cédito, subrogación em La posición deudora de um tercero e, em general, mediante caulquier outra operación financiera Del Estado, com destino a financiar los gastos del Estado con destino a financiar los gastos Del Estado o a constituir posiciones activas de tesoreria”.

35 Deuda Pública y otros ingresos públicos ceditorios. Miguel Angel Luque Mateo e Marian Aguilar Rubio, de Miguel Angel Collado Yurrita e Gracia Maria Luchena Moro, ed. Atelier, Barcelona, 2010, pp. 77-95.

36 Comentários à Lei de Responsabilidade Fiscal, coord. Ives Gandra da Silva Martins Carlos Valder do Nascimento, Editora Saraiva, 2008, p. 192. 
cem regime jurídico especial, e entre nós bastante rigoroso, especialmente considerando a chamada Lei de Responsabilidade Fiscal.

De certa forma, podemos inferir que a dívida, o fato de dever, de utilizar-se do crédito nas suas variadas formas legais, não é um mal em si que possa ou deva ser evitado a qualquer custo. Diversamente, uma questão que se põe diz respeito à qualidade dele, que se refere à utilidade social tendo em conta a equação custo-benefício, a adequação da finalidade, do objetivo, os resultados incrementais e o gerenciamento do pagamento.

Portando, a dívida em si não é propriamente o eixo, o é sim, a qualidade do endividamento, o emprego do recurso objetivo na via do crédito, os resultados concretos advindos o emprego dos recursos.

Nos Estados complexos organizados em federação, como é o caso brasileiro, e ilustramos com o caso sui generis das autonomias espanholas, é o mosaico de ordenamento financeiro, obtenção e aplicação de recursos, controle e fiscalização, gestão de pagamento e de ressarcimentos que se dá em polos diversos de poder político, porque atuações existem do Estado Nacional, como podemos considerar o poder central e dos diversos polos de poder das unidades componentes que são dotadas de autonomia, e, como tal, tem atribuições e competências juridicamente fixadas, bem assim como fontes de custeio. Dessarte, todo o sistema precisa compatibilizar as contas locais com as nacionais, e, considerando que as contas nacionais incluem as das unidades, tal harmonização ao mesmo tempo em que precisa trazer certo grau de impositividade do nacional sobre o local, está, igualmente, obrigada a respeitar a autonomia.

Não é uma equação simples.

Os Estados membros da Federação têm atribuições constitucionalmente estabelecidas na repartição das competências, relevando destacar que este conjunto de competências é marcado pela isonomia, porquanto todos têm as mesmas competências no âmbito de seus territórios, e a base econômica de sustentação, que serve de substrato material para a receita via tributação, não é simétrica, bem ao contrário, é extremamente desigual. É flagrante o desequilíbrio e as diferenças econômicas e sociais entre os diversos entes da federação, do que resulta que a capacidade arrecadatória é desigual, e, não raro, insuficiente. Existem, é verdade, mecanismos derivados do federalismo solidário que servem de redistribuição de recursos com transferências, sempre através do poder central, de unidades mais ricas, para unidade mais pobres. Mas, a experiência tem demonstrado que tais instrumentos, inobstante sejam empregados, não são suficientes.

Tem-se um quadro de permanente endividamento das unidades federativas e uma sempre dramática situação de capacidade real de pagamento, acentuando-se que os custos da dívida reduzem fortemente a capacidade de prestação de serviços 
públicos e de investimentos no âmbito do que lhes cabe fazer, o que contribui decisivamente para a manutenção de um quadro de permanente precariedade, de instabilidade mesmo, porque periodicamente acontece a sufocação financeira com a necessidade de revisão do processo, que, como se observa, tem a característica da precariedade e da transitoriedade, apenas adiando, projetando no tempo o mesmo problema, que reincidentemente acontece de tempos em tempos.

Quando se cogita de dívida pública, precisa-se ter em vista a ideia de real solução do problema, de uma revisão real, do estabelecimento de paradigmas com limitações e condicionamentos que, ao longo do tempo, levem o processo à solução, a solvabilidade, a capacidade funcional plena e, consequentemente, a confiabilidade necessária à gestão pública, de nada adiantando os discursos de cunho moralista que, limitando-se à crítica, mesmo fundada, omitem apontar caminhos e opções reais de tratamento do problema.

\section{CONCLUSÃO}

Parte-se do pressuposto de que é frequente a ocorrência de déficit, e, ainda, que o enfrentamento do quadro se dá pelo endividamento. Assim, estes irmãos siameses, déficit/dívida, estão, portanto, presentes na vida financeira do Estado contemporâneo, integram o universo das vicissitudes da contemporaneidade até, como consequência da precária estabilidade das coisas inerente a nosso tempo, a questão posta é como tratar o tema de maneira a ser possível encontrar saídas viáveis, concretas e objetivas.

A norma que materializa a "regra" ou "cláusula" de ouro é uma proposta que se julga adequada para enfrentar o angustiante problema. Porém, crê-se que se pode e deve ser aperfeiçoada, não bastando a vedação de constituir dívidas para cobrir despesas correntes e de custeio, nem limitação de despesas sobre determinados itens como pessoal, nem mesmo o estabelecimento de teto de crescimento de despesas com base em cálculos de quaisquer referências. É fato que tudo isto contribui para o equilíbrio orçamentário, mas seguramente não basta, como o demonstra, e à saciedade, a experiência.

A cláusula de ouro precisa estabelecer não apenas um teto para o déficit orçamentário (talvez em percentual do PIB), mas precisa estipular um prazo para a correção e a exigência de um plano objetivo de ação para a redução dele; o mesmo devendo acontecer em relação ao endividamento.

Há necessidade, porém, de adoção de mecanismos preventivos com a fixação de instrumentos de verificação, ao longo do exercício, da formação, aumento ou redução do déficit e da dívida, o que pode e deve acontecer pelo rigor com a qualidade das despesas (uteis e produtivas), de forma a permitir pelo menos a mino- 
ração razoável da tendência antes da consumação do quadro, além de preparar medidas subsequentes para a restauração da situação.

Um recurso importante é a adoção da realidade/orçamentária, no sentido de que os parâmetros e indicadores para a estimação das receitas e despesas seja o suficientemente realista, de sorte a que a execução orçamentária e o controle e fiscalização pertinentes sejam eficazes, demonstrando que a aplicação descuidada ou incorreta dos mecanismos de qualificação de despesas, de estimativa de receitas e renúncias fiscais configurem ilicitudes jurídico-financeiras, ensejando responsabilidade, não apenas política, mas, também, de cunho de probidade e, eventualmente, até mesmo civil e penal daqueles que pratiquem os atos.

É importando reforçar que quando se cogita da apresentar os elementos capazes de enfrentar a problemática do déficit/dívida pública, se o faz considerando a totalidade estrutural do Estado (brasileiro), o que significa a adoção de sistema legislativo nacional, com eficácia e vigência ao longo de toda a Federação, envolvendo União, Estados e Municípios, de sorte da proporcionar o controle jurídico eficaz das contas públicas de cada um dos entes federativos e do conjunto do Estado.

Tem-se a mais absoluta convicção de que o Direito Financeiro tem papel de fundamental importância no Estado contemporâneo, e pode dar contribuição essencial ao bem estar social, ao desenvolvimento econômico e social, e, principalmente, a efetivação dos Direitos Fundamentais, tudo remarcado pela necessária transparência para que a sociedade possa compreender e acompanhar o desenrolar do processo de gestão financeira, aprofundando, assim, o conteúdo democrático do sistema jurídico-político, consolidando o caminhar para o exercício pleno e integral da Cidadania Fiscal.

\section{REFERÊNCIAS}

ABRAHAM, Marcus. Curso de Direito Financeiro Brasileiro, Ed. Elsevier, 2010.

ALBERT, Jean-Luc; SAIDJI, Luc. Finances Publiques, Dalloz, Paris, 2011.

BALEEIRO, Aliomar. Uma Introdução à Ciência das Finanças, ed. Forense, RJ, 2012.

BASTOS, Celso Ribeiro. Curso de Direito Financeiro e Tributário, ed. Celso Bastos, SP, 2002.

BEREIJO, Álvaro Rodriguez. Laband, Paul. Derecho Presupuestário. Ed. Tecnos, Madrid, 2012.

BITAR, Orlando. Estudos de Direito Constitucional, ed. Renovar, RJ, 2008.

CARRAZZA, Roque Antônio. Direito Constitucional Tributário, ed. Malheiros, 2013. CAZORLA Prieto, Luis Maria. Derecho Financiero y Tributário. Thomson Aranzadi, Navarra, 2007. 
DOMINGUES, José Marcos. Equilíbrio orçamentário vai muito além da projeção financeira. Consultor Jurídico - Conjur, 10/12/14, disponível em: https://www.conjur. com.br/2014-dez-10/jose-domingues-equilibrio-orcamentario-projecao-financeira. FONROUGE Giuliani, Carlos M. Derecho Financiero, Tomo I, ed. La Ley, Buenos Aires.

GONZALES, Eusebio. Derecho Financiero y Tributário, Ed. Salmantina, s/d.

HORTA, Machado. Estado Federal e Tendências do Federalismo contemporâneo, Direito Constitucional. Ed. Del Rey, BH, 2010.

JÈZE, Gaston. Cours Élémentaires de Science dês Finances et de Législation Fianciére Française, Ed. La Memoires Du Droit, Paris, 2010.

LAPAZA, José Juan Fernando. Instituciones de Derecho Financiero, Ed. Marcial Pons, Madrid, 2010.

LUQUE Mateo, Miguel Angel; RUBIO, Marian Aguilar. Deuda Pública y otros ingresos públicos ceditorios. de Miguel Angel Collado Yurrita e Gracia Maria Luchena Moro, ed. Atelier, Barcelona, 2010.

MARTINS, Ives Gandra da Silva coord. NASCIMENTO, Carlos Valder do. Comentários à Lei de Responsabilidade Fiscal, Editora Saraiva, 2008.

MELO Franco, Afonso Arinos. Teoria da Constituição. ed. Forense, RJ, s/d.

OLIVEIRA, Régis Fernandes de. Curso de Direito Financeiro, Ed. RT, SP, 2015.

PONTES Lima, Edilberto Carlos. Uma Introdução à Ciência das Finanças, ed. Forense, RJ, 2012.

ROSA Junior, Emygdio F. da. Manual de Direito Financeiro \& Tributário, Ed. Renovar, RJ, 2010.

TAVARES, André Ramos. Curso de Direito Constitucional, ed. Saraiva, SP, 2010. TROTABAS, Louis. Precis de Science et Legislatión Financieres, Ed. Dalloz, Parias, 1938. 
